\title{
Presenting Artistic Performance: Considering Management \& Product
}

\author{
Rahmah Bujang \\ Professor Emiritus \\ Universiti Malaya, Malaysia \\ rahmahbuja@gmail.com
}

\begin{abstract}
The paper sets out to emphasize the importance and symbiosis between management and product derived in developing an artistic presentation. An artistic performance is the result of group effort working together in consonance. To achieve that there need to be, firstly, knowledge ownership in the creative art of choice. Secondly, ability and confidence to create the work much to the aesthetic satisfaction of its social milieu. Thirdly, in managing the work process itself. Fourthly, the gratification received by those involved in its development; satisfied in the knowledge that presenting a creative performance demands foresight, perseverance and leadership.
\end{abstract}

Keywords—artistic performance, symbiosis, aesthetic, management, leadership.

\section{INTRODUCTION}

Discussion in this paper is based on various motivational factors. Firstly, that as human beings we must realize that our potential are limited to only what we know; that above all humankind and all living things exist because of the absolute power of Rabbalalaminand kunfayakun. Secondly, that in developing artistic creative works humans need to work together with an open mind and in the spirit of concerted expressive realization for the betterment of mankind. Thirdly, that within the current state of advancement in the world any effort at production requires organizational impetus and impact to establish results. Fourthly, that whatever the satisfaction derived at the end result, it is very much confined within the purview of effort that has been put into the creative work. Only too true is that those embroiled in the process of art expression are very much aware of the type of focus required emotionally, intellectually and physically for them.

Fascinating though is how one imbued with the gift of creativity will still empower themselves to get involved. I am indeed reminded by the comments made by Maya Angelou (born 4/4/1928 died 28/5/2014), when she said: "You can't use up creativity. The more you use, the more you have." Being herself involved for over 50 years in the world of creative enterprise such words became her right especially after knowing that Maya Angelou had boundless energy being a social activist preoccupied with the creative activities of literature, dance, song and published her own works. She herself was in her lifetime an embodiment of endless creative drive and ability.

It must be recognized that any artistic endeavours, like other endeavours too, lies in the challenge of management as the most daunting task for members. But it is not without its reward for creative activity does give both short and long term gratification. Especially meaningful is the gratification linked to artistic conception and perception culminating in creative presentation that help to create social awareness.Naturally not anyone can rise up to the occasion, nor can just one person work alone. With globalisation and expansion of education, the creative enterprise is best developed via knowledge of the creative vehicle of choice. Concurrently the needs of the public upon which the creativity is presented must be understood and addressed for garnering real appreciation to the works. Thus any creative production need to connect via the creative medium with the support andparticipation of academia, current world trends, and faith of both parties involved, which are the creative exponents and the social milieu they are addressing. Indeed one cannot ignore the creative arts that seem to defy conformity which however upon closer scrutiny are in actuality expressions that conform to life's peculiarities. Or for that matter realizing upon creative works that could be mundane without its guise into expressions using the cloak of experimentalism, symbolism, expressionism and abstractionism or just simply elevated through the use of computationism.

\section{DISCUSSION}

Performance Arts as A Creative Endeavour

Uppermost in any creative endeavour is the process of its development within a clear stated planning structure, and the hope that the final presentation become accepted as a work of art fulfilling certain easthetic values. So what are meant by art and aesthetic fulfillment?

From the onset art and aesthetics need to be etimologically understood. The word aesthetics is derived from the Greek wordaisthēsis, which refer to perception and sensibility. Since the $18^{\text {th }}$ century this concept has been discusssed. Alexander Baumgarten defined aesthetics as "the science of sensory knowledge directed toward beauty" and in connecting to the concept of 
art he said art is "the perfection of sensory awareness" (Frankfurt, 1750). Thus aesthetics being sensoryknowledge is very much a reflection of life and the dynamism of the people under its purview; characterized by the level of material and intellectual (hovering on social, cultural, political elements) entities of civilization within which the artistic product emerges. At the present time aesthetics has become generally applied as a standard for measuring beauty and comfort, demonstrating human sensory capacity and need for the comforts of life which, by the way, becomes more demanding as civilization advances.

As a science of sensory knowledge, Baumgarten raises the meaning to the technicalities of the definition and being related to people's life mannerism and achievement, its study quickly became a branch of the discipline in philosophy. The study of aesthetics is now a strong philosophical disiplinary area embedding understanding and knowledge of its value to society both manmade and natural within the variants of time and place of art studies as perceived. Art and art aesthetics is seen as readily evaluated using cognitive and emotive values.For example, Reber and Schwarz put forward the feeling-as-information theory(Reber et. al. , 2004 \& Schwarz, 2012). Indeed Leder and Scherer promotes the notion of evaluation of style and artistry as serious knowledge studies (Leder et.al, 2004 \& Scherer, 2005). Other purviews stresses the importance of emotional evaluation as proposed by Immanuel Kant (1790/2001) with his essential aesthetic stancetheory.

This paper writer herself is prone to perceive and evaluate with fairness and good judgement as a yardstick, more so because in handling the issues of aesthetics one must need to weigh intellectual attainment of the perceiver in having sharp sensory perception and clear conception initiated and realized by the strength of one's own social and cultural conviction. The writer's point of view runs consonant with an article seen in the British Journal of Psychology(2004), 95, 489-508 published by The British Psychological Society; wherein in the article titled "A model of aesthetic appreciation and aesthetic judgments" by Helmut Leder, et.al.; in essence link aesthetics to psychology when a passage read:

"art appreciation more than ever before requires explicit information processing...the investigation of aesthetic experience has mainly been a discipline of visual perception, with a clear focus on the visual properties of artworks or art-like stimuli. Although never a broad area, there is now considerable knowledge about what visual properties bear the potential to be aesthetically experienced or at least affect aesthetic preferences." (2/20)

Upon digesting the contents of the passage above in the article by Leder dan friends, I too carry the conviction that appreciation and interpretation of any art work must start from your very own experience and perception in order to justify the quality of the product. It is no surprise that the same tools are used by all evaluators in surveying a presented product. The difference, which I see as an enriching factor, is the cultural and social upbringing of the evaluator. Mostly artistic products are measured by the following considerations:

1. Has it got an understandably definite style?

2. Examining selected interactions and discussion with reference to:

A. Unity of perception in the work (its delivery and symbolism, if any - enabling semiotics of meaning, situation and context).

B. Clarity of classification (such as affirming on genre and style).

C. Cognitive mastery (usually proven via affective, emotional and feedback as instrumentation).

3. Its relation to sensitivities of feeling and socio-cultural links, which include:

A. Memory integration (unavoidable because participation include the participant's socio-cultural background).

B. Motivating evaluation (more often than not based on personal or group satisfaction rising from sense and thought, or both).

Bearing in mind that no effort can be credited to just one person or persons, especially in presenting performance art; a just evaluation must need to consider group affiliation, group effort, and group dynamism. Group members may individually differ in emotional and intellectual achievements, but their effort as a group can be standardized by counter checking, as listed below:

1. The group must have accepted and adopted the style of choice.

2. All members have some knowledge of the how and why they involve themselves in the production - what is their motivation?

3. Ability and staying power to keep involved.

4. Be strategically proactive and ready. 
Then, and only then, can the evaluation meet some measure of justification; for such considerations as mentioned above are based on administering and managing a production presentation. Its study need to include group achievement within the basis of clearness of production strategy, availability of financing and sponsorship, and finally the end result in the production itself.

\section{Performance Success Attributed to Management}

It is a stated order of things that any development of creative enterprise requires a team of people to realize its potential. Their role is to take on their various assigned tasks responsibly. For the Malays there is even an adage from days of yore highlighting its wisdom, which literally means all work will be successfully done with teamwork; as below:

"Bulat air dek pembetung, bulat kata dek muafakat."

Teamwork can be interpreted as such:

1. Working in tandem on a specific strategy.

2. Available finances.

3. Working with product end in mind.

Its execution lies in the motivational impact and initiative of the leader in the group and the maturity of the group members as a support system. Everything boils down to the ability of the machinery involved in the management process. The real test is in making sure things are carried out as planned. The real reward is in the feeling of mental and emotional strength of those involved in the production.

\section{Developing Performance Creativity-Examples Considered}

For the purpose of enlightenment, I have set out to show three examples as real case studies. All three are chosen by virtue of their differing potentials and stated objectives. The first group set as an example is Creative Performance Limited (CPL) which hails from England. Two other examples are taken from groups active in Malaysia: Instant Café Theatre (ICT) and Kaki $\operatorname{Seni}(\mathrm{KS})$.

\section{Creative Performance Limited}

From their website (creative.performance@yahoo.co.uk), it becomes very clear that this group operate as a creative non government organization (NGO) focusing on working with and for underprivileged children of five years age and above. The group's mission is to develop the children's confidence and awareness using the medium of movement and speech art. The aim is to create for them a safe and happy environment while being involved. The group's motto is stated as "Every Child Matters" embedded in this principle of which are the following strategies:

A. Maintaining safety: taking responsibility over the safety of every child involved in the organizational activities.

B. Maintaining health: encouraging them to pursue physical and mental health.

C. Interesting and achievable: offering kids involved good life practices whilst shaping their potential for teenagehood.

D. Providing positive contribution: involving children with the group fulfills their role for community and society harbouring the children from negative antisocial elements.

E. Balancing the economy:since every child within its fold is not hindered by poverty or unavailable resources to be able to reach out and enjoy life to the full.

Creative Performance Limited gave public recognition in their website to companies that has contributed financially, giving mileage to the Social Corporate Responsibility of these companies; some of which as stated are Brent Connexions, Pet Allianz, Brent Grassroots; as well as acknowledging fellow organizations as support systems such asFair ShareandNorth West London Community Foundation.

The group's action plan goes along the line of (see illustrations of end result below):

1. Education: conducting workshops on creative performance methods, planning production activities, and finance resourcing workshops.

2. Roping in local artists: to help in performing, carry out workshops and sharing of experience.

3. Developing and presenting performances: always children based activities using the medium of:
A. Dance, mime, drama, and story telling
B. Sessions to heighten performance activities via physical theatre
C. Art crafts and music. 

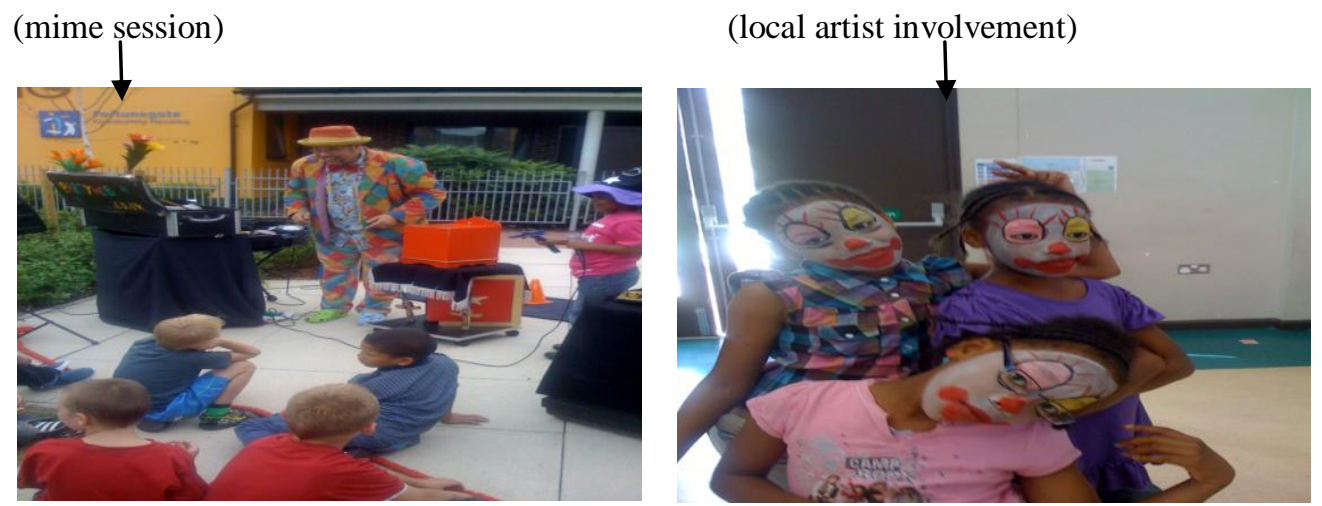

Fig. 1. Mime (downloaded 16th April 2015 at http://creativeperformance.org/images/IMG_0480.JPG)

\section{Instant Café Theatre}

Information gleaned fom this group (admin@instantcafe.com) points to them as involved in using the performance medium as an alternative voice for the people in their fold. The target group is largely youths, giving them a chance and means to express the often misunderstood complex social Malaysian society. Thus it is not surprising that this group finds their best expressions using satirical plays, usually treating political bias most of the time. The group's website ambitiously lauds the words:

“...treat the great themes of modern life: HOME, HISTORY, FOOD, MIGRATION, TABOOS, BEAUTY,

DEATH, CLIMATE, TRAVEL and HERITAGE.”

It is only natural as an alternative voice of youth that the group go by the adage of: "biting the hand that feeds and nurturing". The group's activities include: Help initiate the development of new drama works via their FIRSTWoRKS program providing platform for young playwrights develop an alternative narrative.

A. Involving participants from all ethnic background residing or citizens of Malaysia.

B. Encourages creativity in all languages, although the most popular medium are English.

C. Stated preference is freedom to be on their own such as generating their own income via their cafetaria Cafe House of Art and Idea (CHAI); although welcoming sponsors and donors. CHAI as cafetaria serves the other purpose of social interaction among members supposedly to encourage proliferation in artistic thinking.

Thus far the group has been quite vocal in producing the "other" voice of the people. Their style seems to dwell upon an experimentation style; using the concept of creative experimentation to produce alternative versions of social and cultural integration; final presentation resultusually bending towards a political satire in the works. Example is this photos of production in 2014.

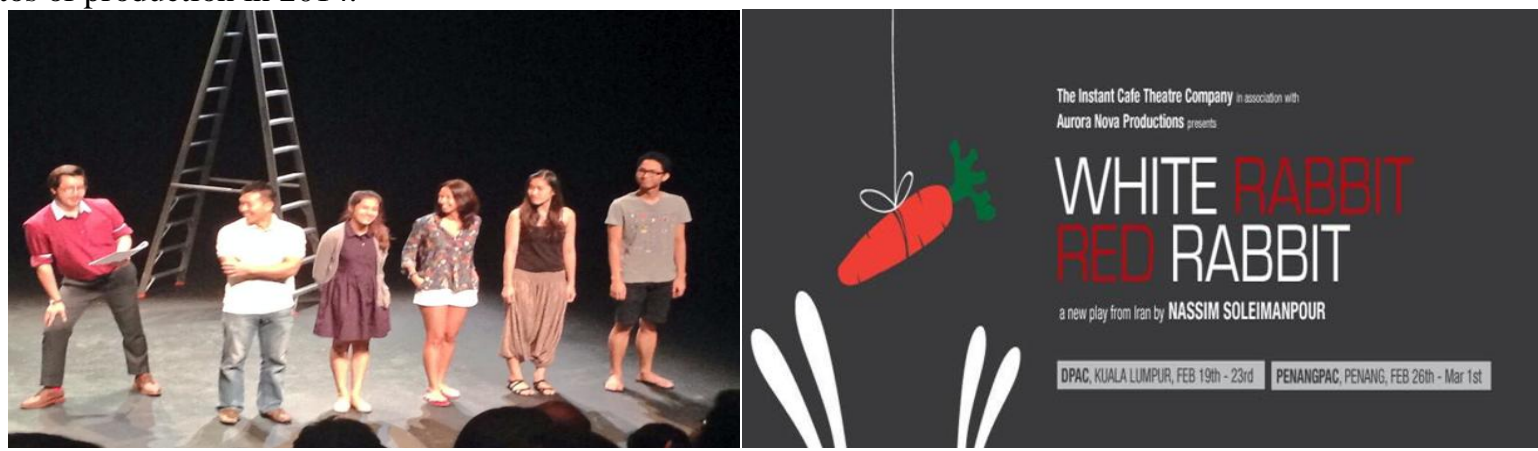

Fig. 2. "White Rabbit Red Rabbit" was performed at Durham PAC in USA, at IPAC Kuala Lumpur, and PAC in Penang. (download 6th May 2015 fromhttps://twitter.com/ICTweets ).

3. Kaki Seni 
This group goes by the motto of "small team with a big heart for the Arts". The group is focused in their objective in being involved in the performance art with the expressed motive to serve as an advisory body for struggling or new creative groups. In their website http://kakiseni.com/the group reaches out to their public with the stated aims of "it's about believing that good things should be shared. We are convinced more people should have access to the performing arts and we are certain that when people get together to have the same conversation, it makes for an enriching experience." To that end the group is resolved"to work with artists to empower the arts industry, and help build a sustainable local arts scene through various efforts".

True to form, the group has experienced some success to that end. Some of their achievements include helping to manage:
A. Bootcampseni \& BOH Cameronian Arts Awards (Project Leader: Lynn Loo: 1ynn@kakiseni.com)
B. DIY Malaysia (Project Leader: Colleen Chung:colleen@kakiseni.com)
C. Kakiseni Blog \& Social Media (Project Leader: Lainie Yeoh: lainie@kakiseni.com)
D. Kakiseni International Arts Festival (Project Leader: Angie Lim: angie.lim@ thecapricomm.com)
E. The Other Festival (arts, history \& food in Ipoh) (Project Leader: Lim Ee Loe: eeloe@ kakiseni.com)

Kaki Seni has also created a form of management aid to help those groups in need to help them garner financial aid, which is done through their sub-section called Grant to Reduce Production Costs (Project Leader: Colleen Chung: email address (grants@kakiseni.com)

\section{Conclusion - Consonance or Disonance?}

\section{CONCLUSION}

Just using the three groups in question as our yardstick, the paper writer is happy to note that to be involved actively in the arts is summarily made possible with holding the key to management knowhow. Operationally however they have their own styles of management. Kaki Seni (KS) operates on a clearcut responsibility given one person with the title of Project Leader, who holds responsibility for the group. Creative Performance Limited (CPL) believe in sharing their responsibilities with having a leader and sub leadersand not naming their specific roles. In the group's website there are many names credited as Directors, names like Bates, Hopeton Walker, Georgina Pennant, Ropo Babalola, Atiya Munir, Cemanthe Harriesare all listed as Directors. Instant Café Theatre (ICT)spread out their group's management responsibilities more clearly than CPL; and so we have names like Jo Kukathas as Artistic Director, Zalfian Fuzi as Associate Director, Rahel Joseph as Director of Programming at CHAI, and Andre D'Cruz as Administrator. More importantly clear is that each group kept to one creative end game - CPL on children's creativity, KS on offering management knowhow, and ICT on aspiring to be self sufficient so they can keep at doing political satires with no qualms. Whatever it is, all three groups demonstrate succinctly the truth of the adage mentioned earlier in this paper - "bulat air dek pembetung, bulat kata dek muafakat".

Another realization is how each group who wants to be active in presentation of their creative enterprises must need to be kept abreast with the times. In this instance, the writer is talking about using mechanization of modern day civilization to project their "faces". Even the paper writer, under various constraints, must rely largely on that mechanization; I am referring here to the availability of websites, and other social medium in the internet like that of facebook and twitter. A daunting process indeed for the groups concerned to having to always bring it up to date; and for the researcher in having to sieve through the internet to find the perfect choice.

In the final analysis, from the three examples portrayed, it can be deducted that any development of performance art activities is driven by each of their stated objectives. Be it for the betterment of children, for the creative expressions by youths, or for the elevation of managerial knowhow in the arts; one similar thing is felt despite their differing outlooks, and that is the way the group find gratification, for themselves, and hopefully, for others. Being gratified is in having the creative knowhow, being able to come together and actively offer something to their public. In the long run each of the group's stamina can only be measured by their discipline and ability to fulfillment of purpose.

As an endnote, when all is said and done; I am yet reminded of this revelation in the Al-Quranwhich in essence speak of God's creation of the heavens and the earth ... all of nature... and the changes into night and day... wherein lies the signs of God's Almighty...wherein the ending for the surah calls upon human(for those who want) to think on itwith intelligence. (Surah Al$R a^{\prime} d 2,3,4: 48$ ). And while we remain staunch in the belief that in God Almighty(Allah Rabbalalamin) we seek guidance;we could also tap on our intelligence so that perhaps,pertaining to the discussion of the paper itself, we can also discover our identity from the various mirrors that humankind can put up in performance presentation, and sothat as humans we can indeed choose to take what is good and discard what is bad for us.By the grace of God, InsyaAllah.

\section{References}

Al-Quran Mushaf Malaysia dan Terjemahan. 2009. Shah Alam, Selangor: Yayasan Restu.

Apter, M. J. (1984). "Reversal theory, cognitive synergy and the arts". Dalam W. R. Crozier \& A. J. Chapman (Eds), Cognitive processes in the perception of art. North-Holland: Elsevier (pp. 411-426). 
Berlyne, D. E. (1974). Studies in the new experimental aesthetics. New York: Wiley.

Crozier, J. B. \& Chapman, A. J. (Eds) (1984). Cognitive processes in the perception of art. North-Holland: Elsevier.

Csikszentmihalyi, M. (1999). "Implications of a systems perspective for the study of creativity". Dalam R. J. Sternberg (Ed.), Handbook of creativity.Cambridge: Cambridge University Press (pp. 313-335).

Dewey, J. (1934). Art as experience. New York: Minton, Balch.

Forgas, J. P. (1995). "Mood and judgment: The Affect Infusion Model (AIM)". Psychological Bulletin, 117, (pp. 39-66).

Goodman, N. (1976). Language of art. Indianapolis, Indiana: Hackett.

Gordon, P. C., \& Holyoak, K. J. (1983). "Implicit learning and generalization of the 'mere exposure' effect". Journal of Personality and Social Psychology, 45, (pp. 492-500).

Kant, I. (1790/2001). Critique of Judgement. Hamburg: Meiner.

Leder, H., Belke, B., Oeberst, A., \& Augustin, D. (2004). A model of aesthetic appreciation and aesthetic judgements. Dalam British Journal of Psychology, 95, (pp. 489-508).

Moles, A. (1968). Information theory and aesthetic perception. Urbana, Illinois: University of Illinois Press.

Rahmah Bujang. (2007). Wadah wahana seni persembahan. Kuala Lumpur: Akademi Pengajian Melayu, UniversityMalaya.

Rahmah Bujang. (2015). Seni ekspresi kreatif. Kuala Lumpur: Akademi Pengajian Melayu, University Malaya.

Reber,R., Schwarz, N., \& Winkielman, P. (2004). Processing fluency and aesthetic pleasure: Is beauty in the perceiver's processing experience? Dalam Personality and Social Psychology Review, 8, (pp. 364-382).

Schwarz, N. (2012). Feelings-as-information theory. Dalam Handook of theories of social psychology; London: Sage (pp. 289308).

Scheerer, K. (2003). "Introduction: Cognitive components of emotion". Dalam R. J. Davidson (Ed.), Handbook of affective sciences; Oxford: Oxford University Press (pp. 563-673).

Scherer, K. R. (2005). What are emotions? And how can they be measured? Dalam Social Science Information, 44, (pp. 695-729). http://en.wikipedia.org/wiki/Alexander_Gottlieb_Baumgarten

https://en.wikipedia.org/wiki/Maya_Angelou

http://blog.instantcafetheatre.com/about/

http://creativeperformance.org/index.html

http://creativeperformance.org/images/IMG_0480.JPG

http://kakiseni.com/ 